\title{
The importance of non-regional lymph nodes in assigning risk in primary metastatic prostate cancer.
}

DOI:

10.1111/bju. 14400

\section{Document Version}

Accepted author manuscript

Link to publication record in Manchester Research Explorer

\section{Citation for published version (APA):}

Ali, S. A., Hoyle, A., Mistry, H., \& Clarke, N. (2018). The importance of non-regional lymph nodes in assigning risk in primary metastatic prostate cancer. BJU international. https://doi.org/10.1111/bju.14400

\section{Published in:}

BJU international

\section{Citing this paper}

Please note that where the full-text provided on Manchester Research Explorer is the Author Accepted Manuscript or Proof version this may differ from the final Published version. If citing, it is advised that you check and use the publisher's definitive version.

\section{General rights}

Copyright and moral rights for the publications made accessible in the Research Explorer are retained by the authors and/or other copyright owners and it is a condition of accessing publications that users recognise and abide by the legal requirements associated with these rights.

\section{Takedown policy}

If you believe that this document breaches copyright please refer to the University of Manchester's Takedown Procedures [http://man.ac.uk/04Y6Bo] or contact uml.scholarlycommunications@manchester.ac.uk providing relevant details, so we can investigate your claim.

\section{OPEN ACCESS}


DR. ADNAN ALI (Orcid ID : 0000-0002-8344-3776)

Article type : Original Article

Article category: Urological Oncology

Title: The importance of non-regional lymph nodes in assigning risk in primary metastatic prostate cancer.

Authors: Adnan $\mathrm{Ali}^{1,2 \#}$, Alexander Hoyle $\mathrm{e}^{1,2,3,4 \#}$, Hitesh Mistry ${ }^{5}$, Noel W. Clarke $\mathrm{1}^{1,2,3,4^{*}}$

${ }^{1}$ Genito-urinary cancer research group, Division of Cancer Sciences, Manchester Cancer Research Centre, University of Manchester, United Kingdom.

${ }^{2}$ Belfast-Manchester Movember Centre of Excellence, Manchester Cancer Research Centre, University of Manchester, United Kingdom.

${ }^{3}$ Department of Surgery, The Christie NHS Foundation Trust, Manchester, United Kingdom.

${ }^{4}$ Department of Urology, Salford NHS Foundation Trust, Salford, United Kingdom.

${ }^{5}$ Division of Pharmacy, University of Manchester.

\# Joint first authors

This article has been accepted for publication and undergone full peer review but has not been through the copyediting, typesetting, pagination and proofreading process, which may lead to differences between this version and the Version of Record. Please cite this article as doi: 10.1111/bju.14400

This article is protected by copyright. All rights reserved. 
*Corresponding author:

\title{
Prof. Noel W. Clarke
}

Department of Surgery,

The Christie NHS Foundation Trust,

Wilmslow Road,

Manchester M20 4BX

United Kingdom

Email: noel.clarke@christie.nhs.uk

\begin{abstract}
Objective: To determine the prognostic relevance of non-regional lymph nodes (NRLN) metastases presenting synchronously with bone metastases in metastatic prostate cancer (mPCa) for guiding treatment decisions based on oligometastatic definitions.
\end{abstract}

Patients and methods: Patients diagnosed with mPCa between 2004 and 2013 were identified from the surveillance, epidemiology and end-results (SEER) database and were grouped by metastatic sites into only NRLN, only bone, bone + NRLN and other sites \pm bone/NRLN metastases. Multivariate Cox and competing risk regression analyses were performed to compare risk of all-cause mortality (ACM) and prostate cancer specific mortality (PCSM) associated with bone + NRLN metastases before and after propensity score matching to patients with only bone metastases. This was complemented with landmark and supplementary analyses.

This article is protected by copyright. All rights reserved. 
Results: Of 17,167 mPCa patients identified, $63.1 \%$ presented with only bone metastases, while bone and NRLN metastases co-occurred in $8.9 \%$ of the cohort. On multivariate analyses after adjusting for potential confounders (clinical and sociodemographic), patients with bone + NRLN metastases had a significantly higher risk of ACM (hazard ratio [HR]: 1.161; 95\% confidence interval [CI]: 1.084-1.243, p-value < 0.001) and PCSM (subdistribution HR [SHR]: 1.149; 95\% Cl: 1.067-1.237, p-value $<0.001)$ compared to patients with only bone metastases. Landmark analyses limited to survivors of $\geq 6$ and $\geq 12$ months again demonstrated significantly increased risk of ACM for patients presenting with bone + NRLN metastases compared to patients with only bone metastases. In a subsequent 1:1 propensity score matched cohort of patients with bone + NRLN metastases and only bone metastases, bone + NRLN group had increased multivariate adjusted hazard rates for ACM (HR: 1.202; 95\% Cl: $1.102-1.311 ; p<0.001)$ and PCSM (SHR:1.146; 95\% Cl: $1.044-1.259 ; p=0.004)$.

Conclusions: Patients with concomitant NRLN and bone metastases have an increased risk of death representing a high risk feature when compared to patients with bone metastases alone. The current therapeutic stratification of "low vs high volume" disease does not account for this phenomenon and patients requiring aggressive combination therapy may not receive a maximal therapeutic benefit as a consequence.

Keywords: lymph node, metastasis, prostate cancer, staging, SEER

\section{Introduction}

Metastatic dissemination of prostate cancer (PCa) is a complex multi-step cascade characterized by variable progression patterns and survival outcomes. The current reductionist approach, simplifying biological behaviour by categorizing treatment according to metastatic sites and enumeration has proven successful to a degree but persistent variations in outcomes and treatment responses still

This article is protected by copyright. All rights reserved. 
remain unpredictable. Metastatic prostate cancer (mPCa) patients with bone or visceral metastases are reported to have a poor prognosis compared to those with non-regional lymph node metastases (NRLN) in isolation (1-3). Based on these results, NRLN metastases in isolation can be considered as a low risk feature in mPCa patients. However, a non-negligible proportion of patients present with concomitant NRLN and bone metastases (4-6). Such patients are reported to have a poor overall survival (OS) compared to patients with only bone metastases in the STAMPEDE and TAX 327 trials indicating this as a high risk feature $(4,6,7)$. This has led to uncertainty regarding inclusion or exclusion of NRLN metastases in prominent enumeration based oligometastatic definitions (8-10). A recent review reported that only 2 out of 6 studies and 4 out of 10 ongoing trials are reported to explicitly include NRLN as an enumeration criterion (10). Moreover, "high volume" disease definitions as used in the CHAARTED, GETUG-15 and LATITUDE trials do not consider NRLN metastases (11-13).

The aforementioned trial results demonstrating adverse prognosis of patients with concomitant bone and NRLN metastases may be inferred but not directly extrapolated to a general population based setting, as trials select patients who are generally younger and fitter overall. Thus, it is appropriate to explore the prognostic relevance of concomitant NRLN metastases in patients with bone metastases in a large nationwide population to evaluate their inclusion or exclusion for guiding treatment decisions based on oligometastatic definitions $(11,12,14,15)$.

\section{Patients and methods}

\subsection{Data source}

The United States (US) National Cancer Institute - SEER database documents cancer incidence and mortality data from 18 cancer registries covering approximately $28 \%$ of the US population. We used the November 2016 submission of this database to study the distribution of metastases at first

This article is protected by copyright. All rights reserved. 
presentation and correlate that with survival outcomes, thereby determining the prognostic relevance of concomitant bone and NRLN metastases in mPCa using collaborative staging (CS) parameters (16).

\subsection{Study cohort}

We interrogated the data from 18 SEER registries using the SEER*Stat 8.3.4 software for cases of prostate adenocarcinoma (International Classification of Disease for Oncology, third edition [ICD-O-

3] site code 619 and histologic type code 8140) diagnosed between 2004 and 2013. January $1^{\text {st }}, 2004$ was selected as the inclusion start date to coincide with the incorporation of "CS Mets at dx" into the SEER database. The end date of December $31^{\text {st }}, 2013$ provided at least one year post diagnosis follow up to assess survival $(17,18)$. Patients in the research database with known age, single primary, M1a-c (derived American Joint Committee on Cancer [AJCC] Cancer Staging Manual, $6^{\text {th }}$ edition) and who were actively followed were included. These parameters returned a cohort of 17,199 patients. Following this, we excluded 27 patients with metastatic site coded as 38 (M1b with no other information on distant metastasis), because it was not possible to discern the presence or absence of concomitant NRLN involvement in these patients. Additionally, we excluded 5 patients with missing information on census tract income and education. Following all exclusions, the final study cohort comprised 17,167 men.

\subsection{Sites of metastases}

The CS data collection system is a joint initiative sponsored by the AJCC to streamline staging data collection in cancer registries $(17,18)$. The "CS mets at $\mathrm{dx}(2004+)$ " parameter in the SEER database includes information on metastatic sites at diagnosis. We utilised this parameter to sub-classify patients by metastatic site at diagnosis into 4 groups as follows: only NRLN metastases (codes: 11 ,

This article is protected by copyright. All rights reserved. 
12, 20), only bone metastases (code: 30 ), bone + NRLN metastases (code: 35 ), other sites \pm bone/NRLN metastases (codes: $40,50,58,55$ ).

\subsection{Covariates and study end-points}

We abstracted age at diagnosis, race, year of diagnosis, prostate specific antigen (PSA) at diagnosis, Gleason score at diagnosis, T stage (derived AJCC T stage, $6^{\text {th }}$ edition) and $\mathrm{N}$ stage (derived AJCC $\mathrm{N}$ stage, $6^{\text {th }}$ edition), marital status and SEER registry for each patient. Race was classified as white, African American, and others/unknown. PSA was used as a categorical variable $(<20,20-49.9,50$ 97.9, $\geq 98 \mathrm{ng} / \mathrm{mL}$ or unknown), as SEER categorizes all PSA values $\geq 98 \mathrm{ng} / \mathrm{mL}$ into one category. Gleason score was determined from SEER CS SSFs (site- specific factor) 5 to 10 (19). The highest available Gleason score was abstracted for each patient and categorized as $\leq 7,8,9,10$ or unknown. Additionally, as SEER began recording insurance status from 2007 onwards, we abstracted insurance status (insured, Medicaid, non-insured or unknown) for use in a supplementary analysis limited to patients diagnosed between $2007-2013$.

Furthermore, as SEER does not provide individual patient level socioeconomic status (SES) we also obtained county level SES indicators. We utilized county level income (median household income) and education status (percentage of residents $\geq 25$ years of age with at least a high school education) as proxies for SES by linking to the 2000 USA census and included them as continuous variables (20). The residential status of patients was also determined at the county level by linking to 2013 US Department of Agriculture rural-urban continuum codes, with patients living in a county of fewer than 20,000 residents classed as non-metropolitan and the remaining as living in a metropolitan area (21).

This article is protected by copyright. All rights reserved. 
The primary study endpoint was all-cause mortality (ACM), defined as the time from diagnosis until death from any cause, with patients alive at the end of the study period censored (December $31^{\text {st }}$, 2014). PCa specific mortality (PCSM) was identified using the SEER coded cause specific mortality and evaluated as a secondary endpoint. Patients who died from any other cause were classified as non-PCa specific mortality (NPCSM).

\subsection{Statistical analyses}

To compare baseline clinical and sociodemographic characteristics between patients with only bone metastases and bone + NRLN metastases, categorical variables and continuous variables were compared using the Pearson's chi-square and Mann-Whitney U tests respectively.

To evaluate the primary objective of comparing survival between patients with only bone metastases and bone + NRLN metastases, our statistical analyses comprised two sets of analyses. The first set of analyses compared the survival within the whole cohort. Survival was estimated using the Kaplan-Meier (KM) method and comparisons were performed using the log-rank test and unadjusted Cox models. Cox regression analysis was used to assess the risk of ACM and PCSM was assessed using Fine and Gray competing risk regression with NPCSM treated as competing risk (22). All multivariable models were adjusted for age, race, PSA, Gleason score, year of diagnosis, T stage, $\mathrm{N}$ stage, SEER registry, residence, income, education status and marital status. We then performed a sensitivity analysis to gauge the effect of a potential unmeasured confounder (UC) on the obtained HR of ACM for patients with bone + NRLN metastases from the multivariate Cox regression analysis $(23,24)$. Additionally, to account for more favourable baseline prognosis of patients with only bone metastases, we conducted landmark analyses limited to patients surviving a minimum of $\geq 6$ and $\geq$ 12 months from diagnosis. Furthermore, we also conducted two sets of supplementary multivariate analyses. As a large proportion of patients had unknown Gleason scores or PSA, we excluded these

This article is protected by copyright. All rights reserved. 
patients to rule out any missing data bias and repeated multivariate Cox and competing risk regression analyses as stated above. We also repeated multivariate Cox and competing risk regressions analyses by introducing insurance status as an additional covariate along with the other aforementioned covariates in a subset of patients diagnosed between 2007 and 2013.

We then explored the risk of ACM associated with bone + NRLN metastases using univariate Cox regression analyses in three pre-specified subgroups. First, we explored whether the magnitude of risk of ACM associated with bone + NRLN metastases differed significantly among patients with or without regional lymph node disease. Second, we stratified the cohort by year of diagnosis (2004 2009 vs $2010-2013)$. This was done to rule out any possible heterogeneity due to a substantial change in the therapeutic landscape for castration resistant mPCa (mCRPC) following 2010 with the introduction of newer life prolonging drugs (25). Third, to explore heterogeneity due to variances in data abstraction among different SEER registries, we grouped the SEER registries according to different contract health service delivery area (CHSDA) regions (pacific coast, south west, northern plains and eastern) (Table S1) and then evaluated the risk associated with ACM for patients with bone + NRLN metastases among different CHSDA regions.

In the second set of analyses, we first performed a 1:1 propensity score-matching to account for inherent differences observed in baseline characteristics (26). Patients with bone + NRLN metastases were matched to patients with only bone metastases using the nearest neighbour without replacement on the logit of the propensity score (derived from age, race, year of diagnosis, Gleason score, PSA, T stage, N stage, SEER registry, marital status, residence, household income, education level). The caliper width used was 0.1 times the standard deviation of the propensity score logit (27). Following matching, balance of covariates between the matched groups was checked (28). We then

This article is protected by copyright. All rights reserved. 
repeated multivariate Cox and competing risk regression analyses for predicting ACM and PCSM respectively.

Statistical analyses were done using $R$ statistical package v.3.3.3 (R Project for Statistical Computing, http://www.r-project.org/) or STATA 13 (StataCorp, College Station, Texas, USA). All tests were twosided with a statistical significance set at $p<0.05$.

\section{Results}

\subsection{Cohort characteristics}

We identified 17,167 men diagnosed with mPCa between 2004 and 2013. The majority of the patients presented with only bone metastases (63.1\%). Concomitant involvement of NRLN with bone metastases (bone + NRLN) occurred in $8.9 \%$ of mPCa patients (Figure S1). Patients with bone + NRLN metastases were significantly younger (median 66 vs 71), had higher Gleason score (Gleason score 810 disease: $83.5 \%$ vs $74.5 \%$ ), had higher PSA (PSA $\geq 98 \mathrm{ng} / \mathrm{mL}: 68.4 \%$ vs $51.5 \%$ ), presented with higher T stage (T stage 3-4: $38 \%$ vs $25.1 \%$ ) and had greater involvement of regional lymph nodes (N1: $73 \%$ vs $17.5 \%$ ) compared to patients with only bone metastases (all p-values <0.05) (Table 1 , Table S2).

\subsection{Survival analyses in overall cohort}

The mean and median follow-up times for the entire cohort were 65 (95\% confidence interval [CI]: $64.4-66.2)$ and 63 months ( $95 \% \mathrm{Cl}: 61.6-64.4)$ respectively. $\mathrm{KM}$ analysis showed that patients with bone + NRLN metastases have a significantly decreased OS compared to patients with only bone metastases (median OS: 24 mo vs 29 mo, log-rank p <0.001) (Figure 1). Likewise, CSS was also

This article is protected by copyright. All rights reserved. 
significantly decreased for patients with bone + NRLN metastases compared to patients with only bone metastases (median CSS: 28 mo vs 36 mo, log-rank $p<0.001$ ).

Multivariate Cox regression analyses adjusted for clinical and sociodemographic characteristics demonstrated a significantly higher risk of ACM for patients with bone + NRLN metastases compared to patients with only bone metastases (hazard ratio [HR]: $1.161 ; 95 \% \mathrm{Cl}: 1.084-1.243 ; \mathrm{p}<0.001$ ) (Table 2, Table S3). This significance also held true for increased risk of PCSM on multivariate competing risk regression (subdistribution HR [SHR]: 1.149; 95\% Cl: 1.067-1.237; $p<0.001$ ) (Table 2). Subsequent, landmark analyses demonstrated that the patients with bone + NRLN metastases have a significantly higher risk of ACM compared to patients with only bone metastases in patients surviving $\geq 6$ months (multivariate HR: $1.193 ; 95 \% \mathrm{Cl}: 1.107-1.285, \mathrm{p}<0.001$ ) and $\geq 12$ months (multivariate HR: 1.168; 95\% Cl:1.073 - 1.272, p<0.001) (Table S4).

An additional set of multivariate Cox regression and competing risk regression analyses were repeated after excluding men with unknown Gleason score or PSA. After exclusions, there were 7867 patients with only bone metastases and 1034 patients with bone + NRLN metastases. Patients with bone + NRLN metastases still demonstrated a significantly increased risk of ACM (HR: 1.205; 95\% Cl: $1.107-1.311, \mathrm{p}<0.001)$ and PCSM (SHR:1.199; 95\% Cl:1.095 - 1.313, $\mathrm{p}<0.001)$ compared to patients with only bone metastases. Additionally, multivariate analyses in a cohort of patients diagnosed between 2007 and 2013 included insurance status as an additional covariate. In this cohort there were 7910 patients with only bone metastases and 1224 patients with bone + NRLN metastases. These multivariate analyses also showed a significantly increased risk of ACM (HR: 1.169; 95\%Cl: $1.108-1.266, p<0.001$ ) and PCSM (SHR: 1.197; 95\% Cl: $1.097-1.307, p<0.001)$ for patients with bone + NRLN metastases compared to patients with only bone metastases.

This article is protected by copyright. All rights reserved. 


\subsection{Unmeasured confounder sensitivity analyses}

A UC sensitivity analysis was conducted based on the adjusted HR of ACM for patients with bone + NRLN metastases compared to patients with bone metastasis (HR: $1.161 ; 95 \% \mathrm{Cl}: 1.084-1.243$ ). This explored the extent of imbalance of a UC between the bone and bone + NRLN groups that would be necessary to affect the statistical significance of our results. For instance, for an unmeasured confounder such as number of bone metastasis $\geq 4$ with a prevalence of $\geq 70 \%$ in the bone group and with an associated two-fold increased risk of death (HR 2), the prevalence of $\geq 4$ bone metastases in the bone + NRLN group would have to be $\leq 50 \%$ to influence the estimated HR enough to make the results nonsignificant (lower bound of $95 \% \mathrm{Cl}$ below 1 ) and $\leq 40 \%$ to reverse the

HR below 1 . Overall, the UC sensitivity analyses indicated that a marked difference in the prevalence of a UC associated with a modest risk of death (HR 1.25), or a modest imbalance in the prevalence of a potential UC associated with a high risk of death (HR 3.25) will be required to render our results insignificant (Table 3).

\subsection{Subgroup analyses}

Finally, subgroup analyses did not reveal any heterogeneity in increased risk of ACM associated with bone + NRLN metastases among patients with N1 (HR: 1.322; 95\% Cl: $1.193-1.464, p<0.001)$ or N0 (HR: 1.367; 95\% Cl: $1.201-1.556, p<0.001$ ) disease (interaction $p$-value $=0.638$ ) (Figure S2). Similarly, a significantly increased risk of ACM for patients with bone + NRLN metastases compared to patients with only bone metastases was demonstrated in patients diagnosed before (HR:1.237; 95\% Cl 1.138 - 1.344, p-value <0.001) and after 2010 (HR:1.244; 95\% Cl: $1.125-1.376)$ (interaction $p$-value $=0.912)$.

This article is protected by copyright. All rights reserved. 
Subgroup analyses stratified by geographic regions showed that the patients with bone + NRLN metastases diagnosed within the southwest SEER registries (New Mexico and Utah) were at an increased non-significant risk of ACM compared to patients with only bone metastases (HR:1.320; 95\% Cl: $0.930-1.873 ; p=0.12$ ). Similarly, patients with bone + NRLN metastases were at a nonstatistically significant increased risk of ACM (HR: $1.213,95 \% \mathrm{Cl}: 1.0-1.471, \mathrm{p}=0.05)$ in northern plains (Detroit, lowa). Overall, no significant heterogeneity was seen in increased risk of ACM associated with patients bone + NRLN metastases compared to patients with only bone metastases among different regions.

\subsection{Propensity score matched cohort analyses}

A 1:1 propensity score matching of patients with bone + NRLN metastases to patients with only bone metastases yielded a cohort of 3008 patients. Baseline characteristics were well balanced across all covariates in the matched cohort (Table 1, Table S2). Within this matched cohort, patients with bone + NRLN metastases had a significantly decreased median OS compared to patients with only bone metastases (24 vs 29 months; logrank p-value <0.001) (Figure 1). Furthermore, multivariate analyses again demonstrated an increased risk of ACM (HR: 1.202; 95\% Cl: $1.102-1.311 ; p<0.001)$ and PCSM (SHR:1.146; 95\% Cl: $1.044-1.259 ; p=0.004$ ) for patients with bone + NRLN metastases compared to patients with only bone metastases (Table 2, Table S5).

This article is protected by copyright. All rights reserved. 


\section{Discussion}

Within this large, general population-based analysis of PCa patients presenting with metastases at diagnosis, we report that the combination of metastatic sites has an important bearing on the natural history of the disease. This is exemplified by the increased risk of ACM and PCSM in patients presenting with coexisting NRLN and bone metastases as compared to patients with only bone metastases.

These findings have important implications for guiding oligometastatic definitions and decisions regarding the use of life-prolonging therapies such as docetaxel or abiraterone acetate in hormone naïve mPCa. Currently, there is an on-going international debate regarding the definition and use of "high and low volume" radiological disease burden in directing combination systemic treatment (1113,29). High volume disease at diagnosis currently indicates docetaxel treatment within the hormone naïve mPCa population in some countries (15) based on the findings of the CHAARTED and GETUG-15 studies $(11,13)$. However, this view is not accepted universally following published data from the docetaxel containing arms of the STAMPEDE trial (14,29-32), where there was no observed heterogeneity of effect. This clinical uncertainty is reflected in the recent advanced prostate cancer consensus conference (APCCC) report where $36 \%$ of PCa experts did not agree with the "CHAARTED" definition and $14 \%$ felt that they would administer docetaxel and ADT to patients with any metastatic disease when first presenting, whether "low" or "high" volume (8). Even if the high/low hypothesis is supported by further data from ongoing studies, there is a fundamental flaw in this "CHAARTED" based approach to patients who present with metastases both in NRLN and bone but whose bone metastases number falls below the defined number of 4 (or 3 in LATITUDE trial)(11,12). This is because the NRLN status in the context of bone metastases is not currently acknowledged in high volume "CHAARTED type" definitions. Therefore, volumetric definitions as used in some other ongoing clinical trials which include NRLN in their enumeration criteria might be more appropriate to

This article is protected by copyright. All rights reserved. 
guide risk stratification in mPCa (10). More recently, a panel of advanced PCa imaging experts also recommended ( $85 \%$ consensus) that enumeration based oligometastatic definitions should be pooled over NRLN and bone metastases (9). Our results support this recommendation.

Findings similar to ours have also been previously reported within the STAMPEDE and TAX327 trials $(4,6)$. Evaluation of data from 917 patients enrolled within the control arm of the STAMPEDE trial showed that patients with bone + soft tissue metastases (mainly NRLN) have a worse 2-year OS (75\% vs $60 \%$ ) compared to patients with only bone metastases. Our findings are similar to these and add a greater reassurance that these outcomes also apply to a "real world" non-trial population. The larger scale of the investigation also provides a high degree of confidence that the effect reported herein is a true phenomenon. Similarly, Pond et al. compared OS of mCRPC patients with bone + NRLN metastases to patients with only bone metastases within the TAX327 trial (6). They also reported an increased risk of death in patients with bone + NRLN metastases compared to patients with only bone metastases (HR: 1.37 95\% Cl: 1.17-1.6) for the overall cohort after adjusting for treatment received, baseline pain, Karnofsky performance score (KPS), prior progression type, PSA, tumour grade, alkaline phosphatase and haemoglobin. Furthermore, a recent SEER-Medicare analysis of 4404 mPCa patients evaluated the relationship of metastatic sites to skeletal related events (SRE)(33). This study reported that patients with bone + NRLN metastases have a higher probability of developing SRE compared to patients with only bone metastases ( $52 \%$ vs $46 \%$ ). Taken together these findings suggest that bone + NRLN metastases is an aggressive mPCa phenotype at presentation and continues to be so in the MCRPC setting.

Moreover, our findings also demonstrate an interesting insight into the natural history of the disease. We have yet to explain from a biomolecular perspective why the combined interaction associated with NRLN and bone metastases show a significant reduction in OS when compared to bone metastases alone. However, in our cohort patients with bone + NRLN metastases were

This article is protected by copyright. All rights reserved. 
younger than those with only bone metastases. Furthermore, no heterogeneity in effect was seen between patients with NO or N1 disease and N1 disease status was not a significant predictor in our multivariate models. Therefore, this disease phenotype at presentation may represent an aggressive mPCa phenotype wherein distant haematogenous and lymphatic spread occur simultaneously or in quick succession. Further evaluation of metastatic dissemination patterns in the hormone naïve setting are warranted to evaluate linear progression or metastasis to metastasis spread as reported in $\mathrm{MCRPC}(34,35)$.

These results need to be interpreted with the limitations pertaining to data obtained from SEER (36). The identification of metastatic sites is based on the best available information (clinical/imaging/pathologic) in SEER registries. Therefore, a great share of this information in living patients can be considered to be obtained from conventional imaging and a detection bias due to lower sensitivity cannot be excluded. Current oligometastatic definitions as used in CHAARTED, GETUG-15 and LATITUDE are based on conventional imaging $\left({ }^{99 \mathrm{~m}} \mathrm{Tc}\right.$-methylene diphosphonate planar or SPECT bone scan and CT/MRI cross-sectional pelvis and abdomen \pm chest). These conventional imaging modalities have a lower sensitivity in detecting metastases compared to emerging imaging modalities such as $\mathrm{Na}^{18} \mathrm{~F}-\mathrm{PET},{ }^{68} \mathrm{Ga}-\mathrm{PSMA}-11 \mathrm{PET}$, whole body diffusion weighted MRI etc. With increasing adoption of emerging imaging modalities, a stage migration (very high risk MO to oligometastatic M1) can be foreseen. Therefore, further evaluation of metastatic site and enumeration based definitions using emerging modalities is warranted in future clinical trials. Other variables regarding metastatic burden such as number, size, and location which are being used to further refine risk stratification in the metastatic setting are not recorded in SEER. However, our sensitivity analyses suggested that a moderate imbalance in metastatic site prevalence would not affect our conclusions. We also recognize that a number of other additional prognostic variables such as performance status and alkaline phosphatase are not recorded in SEER and could not be 
included in the analyses, limiting our conclusive ability. Finally, data on systemic therapies were unavailable. However, ADT remained the gold standard for de-novo metastatic patients for the study duration. Furthermore, a subgroup analysis before and after 2010 did not reveal any heterogeneity, ruling out a potential bias favoring improved survival of patients with only bone metastases post 2010 in the mCRPC setting.

\section{Conclusions}

The combination of NRLN with bone metastases is a poor prognostic marker in comparison to patients with bone metastases alone. This should be considered as a high risk feature within metastatic volume stratified definitions to improve the accuracy of disease volume based decisions when considering combination treatments in hormone naïve mPCa. The mechanisms explaining this differential biological effect are poorly understood and further investigations are required to improve the basic scientific understanding of hormone naïve metastatic phenotypes. Prospective volumetric disease quantification, with a precise recording of metastatic sites and burden should be considered as part of future trial designs within hormone naïve mPCa treatment.

\section{Conflicts of interest:}

None declared.

\section{References}

1. Sandhu DP, Mayor PE, Sambrook P, George NJ. Increased survival of patients with massive lymphadenopathy and prostate cancer: evidence of heterogeneous tumour behaviour. $\mathrm{Br} \mathrm{J}$ Urol. 1990 Oct;66(4):415-9.

2. Gandaglia G, Karakiewicz PI, Briganti A, Passoni NM, Schiffmann J, Trudeau V, et al. Impact of the Site of Metastases on Survival in Patients with Metastatic Prostate Cancer. Eur Urol. 2015 Aug;68(2):325-34.

This article is protected by copyright. All rights reserved. 
3. Halabi S, Kelly WK, Ma H, Zhou H, Solomon NC, Fizazi K, et al. Meta-Analysis Evaluating the Impact of Site of Metastasis on Overall Survival in Men With Castration-Resistant Prostate Cancer. 2017;34(14).

4. James ND, Spears MR, Clarke NW, Dearnaley DP, De Bono JS, Gale J, et al. Survival with newly diagnosed metastatic prostate cancer in the docetaxel era: Data from 917 patients in the control arm of the STAMPEDE Trial (MRC PR08, CRUK/06/019). Eur Urol. 2015 Jun;67(6):1028-38.

5. Gandaglia G, Abdollah F, Schiffmann J, Trudeau V, Shariat SF, Kim SP, et al. Distribution of metastatic sites in patients with prostate cancer: A population-based analysis. Prostate. 2014 Feb;74(2):210-6.

6. Pond GR, Sonpavde G, de Wit R, Eisenberger MA, Tannock IF, Armstrong AJ. The prognostic importance of metastatic site in men with metastatic castration-resistant prostate cancer. Eur Urol. 2014 Jan;65(1):3-6.

7. James ND, de Bono JS, Spears MR, Clarke NW, Mason MD, Dearnaley DP, et al. Abiraterone for Prostate Cancer Not Previously Treated with Hormone Therapy. N Engl J Med. 2017 Jun;

8. Gillessen S, Attard G, Beer TM, Beltran H, Bossi A, Bristow R, et al. Management of Patients with Advanced Prostate Cancer: The Report of the Advanced Prostate Cancer Consensus Conference APCCC 2017. Eur Urol. 2017 Jun 24;1-34.

9. Padhani AR, Lecouvet FE, Tunariu N, Koh DM, De Keyzer F, Collins DJ, et al. Rationale for Modernising Imaging in Advanced Prostate Cancer. Eur Urol Focus. 2017;3(2-3):223-39.

10. Tosoian JJ, Gorin MA, Ross AE, Pienta KJ, Tran PT, Schaeffer EM. Oligometastatic prostate cancer: definitions, clinical outcomes, and treatment considerations. Nat Rev Urol. 2017;14(1):15-25.

11. Sweeney CJ, Chen Y-H, Carducci M, Liu G, Jarrard DF, Eisenberger M, et al. Chemohormonal Therapy in Metastatic Hormone-Sensitive Prostate Cancer. N Engl J Med. 2015 Aug 20 [cited 2016 Dec 11];373(8):737-46.

12. Fizazi K, Tran N, Fein L, Matsubara N, Rodriguez-Antolin A, Alekseev BY, et al. Abiraterone plus Prednisone in Metastatic, Castration-Sensitive Prostate Cancer. N Engl J Med. 2017 Jun;377(4):352-60.

13. Gravis G, Boher JM, Joly F, Soulié M, Albiges L, Priou F, et al. Androgen Deprivation Therapy (ADT) Plus Docetaxel Versus ADT Alone in Metastatic Non castrate Prostate Cancer: Impact of Metastatic Burden and Long-term Survival Analysis of the Randomized Phase 3 GETUG-AFU15 Trial. Eur Urol. 2016 Aug [cited 2018 Jan 11];70(2):256-62.

14. James ND, Sydes MR, Clarke NW, Mason MD, Dearnaley DP, Spears MR, et al. Addition of docetaxel, zoledronic acid, or both to first-line long-term hormone therapy in prostate cancer (STAMPEDE): survival results from an adaptive, multiarm, multistage, platform randomised controlled trial. Lancet. 2016 Mar [cited 2016 Dec 11];387(10024):1163-77.

This article is protected by copyright. All rights reserved. 
15. National Comprehensive Cancer Network (NCCN). Prostate Cancer (Version 2.2017). 2017.

16. Surveillance, Epidemiology, and End Results (SEER) Program (www.seer.cancer.gov) SEER*Stat Database: Incidence - SEER 18 Regs Custom Data (with additional treatment fields), Nov 2016 Sub (1973-2014 varying).

17. Howlader N, Chen VW, Ries LAG, Loch MM, Lee R, DeSantis C, et al. Overview of breast cancer collaborative stage data items-their definitions, quality, usage, and clinical implications: A review of seer data for 2004-2010. Cancer. 2014 Dec 1;120(S23):3771-80.

18. CS - Collaborative Stage About CS [Internet]. [cited 2017 Aug 16]. Available from: https://cancerstaging.org/cstage/about/Pages/default.aspx

19. SEER Coding Manual [Internet]. [cited 2018 Jan 2]. Available from: https://seer.cancer.gov/tools/codingmanuals/

20. U.S. Census Bureau. Census 2000. 2002 [cited 2018 Jan 2]; Available from: http://www.census.gov/prod/2002pubs/censr-4.pdf

21. United States Department of Agriculture Rural-Urban Continuum Codes [Internet]. [cited 2018 Jan 2]. Available from: https://www.ers.usda.gov/data-products/rural-urbancontinuum-codes.aspx

22. Fine JP, Gray RJ. A Proportional Hazards Model for the Subdistribution of a Competing Risk. J Am Stat Assoc. 1999 Ju;94(446):496-509.

23. Lin DY, Psaty BM, Kronmal R a. Assessing the sensitivity of regression results to unmeasured confounders in observational studies. Biometrics. 1998 Sep;54(3):948-63.

24. Mitra N, Heitjan DF. Sensitivity of the hazard ratio to nonignorable treatment assignment in an observational study. Stat Med. 2007 Mar 15;26(6):1398-414.

25. D'Amico A V. US Food and Drug Administration approval of drugs for the treatment of prostate cancer: A new era has begun. J Clin Oncol. 2014 Feb 1;32(4):362-4.

26. Rosenbaum PR, Rubin DB. Reducing bias in observational studies using subclassification on the propensity score. J Am Stat Assoc. 1984 Sep [;79(387):516-24.

27. Austin PC. Optimal caliper widths for propensity-score matching when estimating differences in means and differences in proportions in observational studies. Pharm Stat. $2011 \mathrm{Mar}$ 1;10(2):150-61.

28. Ho DE, Imai K, King G, Stuart EA. Matchlt : Nonparametric Preprocessing for Parametric Causal Inference. J Stat Softw. 2011 Jun 14;42(8):1-28.

29. Parker C, Gillessen S, Heidenreich A, Horwich A. Reply to the letter to the editor "Many men with castrate-sensitive metastatic prostate cancer should not receive chemotherapy" by Tannock et al. Ann Oncol. 2016 Apr;27(4):750-1.

30. Tannock IF, Sternberg CN. Many men with castrate-sensitive metastatic prostate cancer

This article is protected by copyright. All rights reserved. 
should not receive chemotherapy. Ann Oncol. 2016 Mar;27(3):545-6.

31. Parker C, Gillessen S, Heidenreich A, Horwich A. Cancer of the prostate: ESMO Clinical Practice Guidelines for diagnosis, treatment and follow-up. Ann Oncol. 2015;26(February 2002):v69-77.

32. Davda R, Hughes S, Jones R, Crabb SJ, Troup J, Payne H. Chemotherapy at First Diagnosis of Advanced Prostate Cancer - Revolution or Evolution? Findings from a British Uro-oncology Group UK Survey to Evaluate Oncologists' Views on First-line Docetaxel in Combination with Androgen Deprivation Therapy in Castrate. Clin Oncol. 2016;28(6):376-85.

33. Hussain A, Aly A, Daniel Mullins C, Qian Y, Arellano J, Onukwugha E. Risk of skeletal related events among elderly prostate cancer patients by site of metastasis at diagnosis. Cancer Med. 2016 Nov;5(11):3300-9.

34. Beltran H, Prandi D, Mosquera JM, Benelli M, Puca L, Cyrta J, et al. Divergent clonal evolution of castration-resistant neuroendocrine prostate cancer. Nat Med [Internet]. 2016;22(3):298305. Available from: http://www.ncbi.nlm.nih.gov/pubmed/26855148

35. Gundem G, Van Loo P, Kremeyer B, Alexandrov LB, Tubio JMC, Papaemmanuil E, et al. The evolutionary history of lethal metastatic prostate cancer. Nature. 2015;520(7547):353-7.

36. Noone A-M, Lund JL, Mariotto A, Cronin K, McNeel T, Deapen D, et al. Comparison of SEER Treatment Data With Medicare Claims. Med Care. 2016 Sep;54(9):e55-64.

Table legends

Table 1: Baseline characteristics of patients with only bone metastases and bone + NRLN metastases in overall cohort and propensity score matched cohort.

Table 2: Summary of hazard ratios from univariate and multivariate Cox and competing risk regression analyses for patients with bone + NRLN metastases compared to patients with only bone metastases.

Table 3: Sensitivity analysis estimating the effect of an unmeasured confounder on adjusted hazard ratio of all-cause mortality for patients with bone + NRLN metastases.

This article is protected by copyright. All rights reserved. 
Figure legend

Figure 1: Kaplan-Meier curves for overall survival for patients with metastatic prostate cancer

stratified by metastatic sites. (A) Overall cohort $(n=17,167)$. (B) Propensity score-matched cohort ( $n=3008)$. NRLN - non-regional lymph nodes.

Table 1 : Baseline characteristics of patients with only bone metastases and bone + NRLN metastases in overall cohort and propensity score matched cohort.

\begin{tabular}{|c|c|c|c|c|c|c|}
\hline & Original coho & & & 1:1 propensi & score matche & cohort \\
\hline & $\begin{array}{l}\text { Only bone } \\
\text { metastases } \\
(n=10840) \dagger\end{array}$ & $\begin{array}{l}\text { Bone and } \\
\text { NRLN } \\
\text { metastases } \\
(n=1523) \dagger\end{array}$ & p-value & $\begin{array}{l}\text { Only bone } \\
\text { metastases } \\
(n=1504) \dagger\end{array}$ & $\begin{array}{l}\text { Bone and } \\
\text { NRLN } \\
\text { metastases } \\
(n=1504) \dagger\end{array}$ & $\begin{array}{l}p- \\
\text { value }\end{array}$ \\
\hline $\begin{array}{l}\text { Age in years, median } \\
\text { (IQR) }\end{array}$ & $71(63-80)$ & $66(59-75)$ & $<0.001^{*}$ & $66(59-75)$ & $66(59-75)$ & $0.452^{*}$ \\
\hline Race, no. (\%) & & & $0.107^{\ddagger}$ & & & $0.573^{+}$ \\
\hline White & $8038(74.2 \%)$ & $1091(71.6 \%)$ & & $\begin{array}{l}1094 \\
(72.7 \%)\end{array}$ & 1079 (71.7\%) & \\
\hline African American & 2005 (18.5\%) & 312 (20.5\%) & & 306 (20.3\%) & 306 (20.3\%) & \\
\hline Other & 797 (7.4\%) & $120(7.9 \%)$ & & 104 (6.9\%) & 119 (7.9\%) & \\
\hline PSA in ng/mL, no. (\%) & & & $<0.001^{\ddagger}$ & & & $0.667^{\mp}$ \\
\hline$<20$ & 1938 (17.9\%) & 146 (9.6\%) & & 139 (9.2\%) & 146 (9.7\%) & \\
\hline $20-49.9$ & $1570(14.5 \%)$ & 144 (9.5\%) & & 159 (10.6\%) & $144(9.6 \%)$ & \\
\hline $50-97.9$ & $1182(10.9)$ & $162(10.6 \%)$ & & $173(11.5 \%)$ & $162(10.8 \%)$ & \\
\hline$\geq 98$ & $4982(46 \%)$ & 980 (64.3\%) & & 931 (61.9\%) & $961(63.9 \%)$ & \\
\hline Unknown & $1168(10.8 \%)$ & $91(6 \%)$ & & $102(6.8 \%)$ & 91 (6.1\%) & \\
\hline Gleason score, no. (\%) & & & $<0.001^{\ddagger}$ & & & $0.674^{\ddagger}$ \\
\hline$\leq 7$ & 2184 (20.1\%) & 179 (11.8\%) & & 160 & 179 (11.9\%) & \\
\hline
\end{tabular}

This article is protected by copyright. All rights reserved. 


\begin{tabular}{|c|c|c|c|c|c|c|}
\hline & & & & (10.06\%) & & \\
\hline 8 & 2107 (19.4\%) & $237(15.6 \%)$ & & $243(16.2 \%)$ & 237 (15.8\%) & \\
\hline 9 & 3587 (33.1\%) & $529(34.7 \%)$ & & $552(36.7 \%)$ & $528(35.1 \%)$ & \\
\hline 10 & 694 (6.4\%) & 139 (9.1\%) & & $146(9.7 \%)$ & $138(9.2 \%)$ & \\
\hline Unknown & $2268(20.9 \%)$ & $439(28.8 \%)$ & & $403(26.8 \%)$ & $422(28.1 \%)$ & \\
\hline $\begin{array}{l}\text { Derived AJCC T stage, } \\
\text { no. (\%) }\end{array}$ & & & $<0.001^{\ddagger}$ & & & $0.671^{\ddagger}$ \\
\hline T1 & $2728(25.2 \%)$ & 281 (18.5\%) & & 288 (19.1\%) & 280 (18.6\%) & \\
\hline $\mathrm{T2}$ & 3666 (33.8\%) & $423(27.8 \%)$ & & 423 (28.1\%) & $422(28.1 \%)$ & \\
\hline T3 & 1004 (9.3\%) & 144 (9.5\%) & & 160 (10.6\%) & 144 (9.6\%) & \\
\hline T4 & $1140(10.5 \%)$ & $288(18.9 \%)$ & & 289 (19.2\%) & 283 (18.8\%) & \\
\hline$T X$ & $2302(21.2 \%)$ & 387 (25.4\%) & & 344 (22.9\%) & 375 (24.9\%) & \\
\hline $\begin{array}{l}\text { Derived AJCC N stage, } \\
\text { no. (\%) }\end{array}$ & & & $<0.001^{\ddagger}$ & & & $0.778^{\ddagger}$ \\
\hline NO & $6321(58.3 \%)$ & $348(22.8 \%)$ & & 341 (22.7\%) & $348(23.1 \%)$ & \\
\hline N1 & $1340(12.4 \%)$ & 939 (61.7\%) & & 913 (60.7\%) & $920(61.2 \%)$ & \\
\hline$N X$ & 3179 (29.3\%) & 236 (15.5\%) & & 250 (16.6\%) & $236(15.7 \%)$ & \\
\hline \multicolumn{7}{|c|}{$\begin{array}{l}\text { Abbreviations: NRLN - non regional lymph nodes, IQR - interquartile range, PSA - prostate specific antigen, } \\
\text { AJCC - American joint committee on cancer. } \\
\text { †Percentages may not add up to } 100 \text { because of rounding. } \\
\text { Statistical test used - *Mann-Whitney U-test, }{ }^{\ddagger} \text { Pearson's chi-square test. } \\
\text { Extended table with additional baseline socio-demographic characteristics are included in the supplementary } \\
\text { materials (Table S2). }\end{array}$} \\
\hline
\end{tabular}

This article is protected by copyright. All rights reserved. 
Table 2: Summary of hazard ratios from univariate and multivariate Cox and competing risk regression analyses for patients with bone + NRLN metastases compared to patients with only bone metastases.

\begin{tabular}{|c|c|c|c|c|}
\hline & $\begin{array}{l}\text { Cox-regression HR } \\
(95 \% \mathrm{Cl}) \text { predicting } \\
\text { ACM }^{*}\end{array}$ & $\begin{array}{l}p- \\
\text { value }\end{array}$ & $\begin{array}{l}\text { Competing risk } \\
\text { regression SHR }(95 \% \mathrm{Cl}) \\
\text { predicting PCSM* }\end{array}$ & p-value \\
\hline \multicolumn{5}{|c|}{ Entire cohort $(n=17167)$} \\
\hline Univariate & $1.224(1.148-1.305)$ & $<0.001$ & $1.256(1.174-1.343)$ & $<0.001$ \\
\hline Multivariate $^{* *}$ & $1.161(1.084-1.243)$ & $<0.001$ & $1.149(1.067-1.237)$ & $<0.001$ \\
\hline \multicolumn{5}{|c|}{ 1:1 propensity score matched cohort $(n=3008)$} \\
\hline Univariate & $1.196(1.097-1.303)$ & $<0.001$ & $1.136(1.036-1.245)$ & 0.007 \\
\hline Multivariate** & $1.202(1.102-1.311)$ & $<0.001$ & $1.146(1.044-1.259)$ & $<0.001$ \\
\hline \multicolumn{5}{|c|}{$\begin{array}{l}\text { *All HR or SHR displayed are for patients with bone + NRLN metastases (patients with only bone } \\
\text { metastases is the reference category). }\end{array}$} \\
\hline \multicolumn{5}{|c|}{$\begin{array}{l}\text { ** Adjusted for age, race, year of diagnosis, PSA, Gleason score, T stage, N stage, residence, income, } \\
\text { education, SEER registry and marital status. }\end{array}$} \\
\hline \multicolumn{5}{|c|}{$\begin{array}{l}\text { Abbreviations: HR - hazard ratio, ACM - all-cause mortality, SHR - subdistribution hazard ratio, PCSM } \\
\text { - prostate cancer specific mortality, PSA - prostate specific antigen, PSA - prostate specific antigen }\end{array}$} \\
\hline
\end{tabular}

This article is protected by copyright. All rights reserved. 
Table 3: Sensitivity analysis estimating the effect of an unmeasured confounder on adjusted hazard ratio of all-cause mortality for patients with bone + NRLN metastases.

\begin{tabular}{|c|c|c|c|}
\hline $\begin{array}{l}\text { Prevalence of } \\
\text { UC in patients } \\
\text { with bone } \\
\text { metastases }\end{array}$ & $\begin{array}{l}\text { Prevalence of UC in } \\
\text { patients with bone } \\
+ \text { NRLN metastases }\end{array}$ & UC HR & $\begin{array}{l}\text { HR }(95 \% \mathrm{Cl}) \text { for } \mathrm{ACM} \text { in } \\
\text { patients with bone }+ \\
\text { NRLN metastases adjusted } \\
\text { for UC }\end{array}$ \\
\hline 40 & 10 & 1.25 & $1.082(1.010-1.159)$ \\
\hline 40 & 30 & 2 & 1.076 (1.004 - 1.075) \\
\hline $40^{*}$ & $30 *$ & $3.25 *$ & $1.023(0.955-1.096)^{*}$ \\
\hline 60 & 30 & 1.25 & 1.085 (1.013 - 1.162) \\
\hline $60^{*}$ & $20 *$ & $1.25 *$ & $1.060(0.989-1.135)^{*}$ \\
\hline 60 & 50 & 2 & 1.086 (1.014 - 1.163) \\
\hline $60^{*}$ & $40 *$ & 2* & $1.014(0.946-1.086)^{*}$ \\
\hline 70* & $30 *$ & $1.25 *$ & $1.062(0.991-1.138)^{*}$ \\
\hline 70 & 40 & 1.25 & $1.087(1.015$ - 1.140) \\
\hline 70* & $40^{*}$ & 2* & $0.956(0.892-1.024)^{*}$ \\
\hline 70* & $50^{*}$ & 2* & $1.024(0.956-1.097)^{*}$ \\
\hline 70 & 60 & 2 & $1.093(1.020$ - 1.170) \\
\hline 70* & $60^{*}$ & $3.25 *$ & $1.059(0.989-1.135)^{*}$ \\
\hline \multicolumn{4}{|c|}{$\begin{array}{l}\text { Abbreviations: UC - unmeasured confounder, } \mathrm{HR} \text { - hazard ratio, } \mathrm{ACM}-\text { all- } \\
\text { cause mortality, } \mathrm{NRLN} \text { - non-regional lymph nodes, } \mathrm{Cl}-\text { confidence interval. }\end{array}$} \\
\hline \multicolumn{4}{|c|}{$\begin{array}{l}\text { *Results indicate scenarios in which lower boundary of } 95 \% \mathrm{Cl} \text { crosses 1, } \\
\text { indicating worse prognosis of bone + NRLN metastases no longer significant. }\end{array}$} \\
\hline
\end{tabular}

This article is protected by copyright. All rights reserved. 

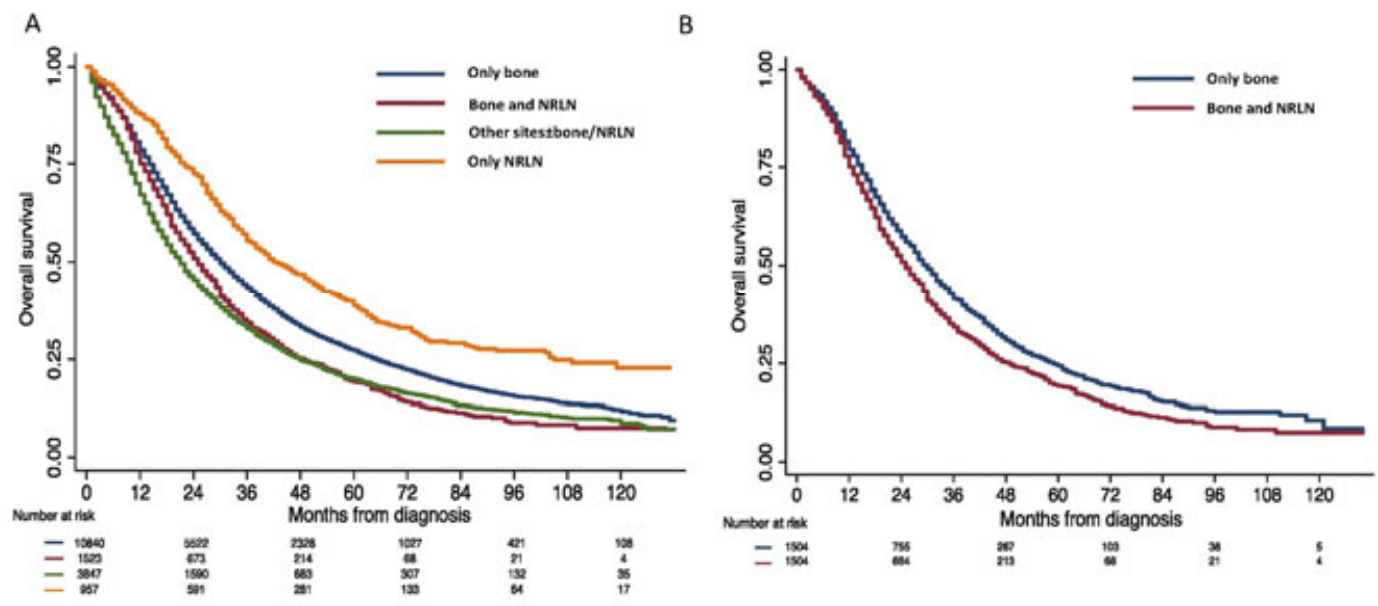

This article is protected by copyright. All rights reserved. 